\title{
Relative significance of environmental factors affecting hydrogen production from landfilled refuse samples
}

The relative significance of 11 environmental factors on the apparent steady-state concentration of hydrogen $\left(\mathrm{ASSCH}_{2}\right)$ achieved during anaerobic degradation of refuse collected from landfills was evaluated by using multiple regression analysis. Simple correlation analysis revealed a significant negative association of $\mathrm{ASSCH}_{2}$ with newsprint moisture content (NMO) and $\mathrm{pH}$ of the sample. Application of five different variable selection procedures, which are commonly used in multiple regression analyses, showed that NMO, amylase (AMY), esterase (EST), cellulose to lignin ratio (CLR), volatile solids (VS), and nitrogen content (NIT) were significantly associated with $\mathrm{ASSCH}_{2}$ simultaneously. The other five factors did not show any significant effect on $\mathrm{ASSCH}_{2}$ in the presence of the six significant factors. Further analysis showed that the influence of AMY and EST on $\mathrm{ASSCH}_{2}$ was weak, hence they were not included in the regression model. CLR was also deleted from the final model because of the multicollinearity resulting from its high correlation with VS. The final model incorporated NMO, $\mathrm{NMO}^{2}, \mathrm{VS}^{2}$ and $\mathrm{NIT}^{2}$; it explained $95 \%$ of the total variability and predicted $98 \%$ of the observed $\mathrm{ASSCH}_{2}$. An assessment of the relative significance of the independent variables indicated that NMO contributed the most, followed by $\mathrm{NMO}^{2}$ and $\mathrm{VS}^{2}$, in that order, and the least by $\mathrm{NIT}^{2}$ towards $\mathrm{ASSCH}_{2}$. The $\mathrm{NMO}$ and $\mathrm{NIT}^{2}$ showed an inhibitory effect on $\mathrm{ASSCH}_{2}$. The results indicated that maintaining optimum moisture, along with optimum organic loading, and nitrogen content in landfills is necessary to achieve and maintain a low $\mathrm{ASSCH}_{2}$ and maximize refuse methanogenesis.

\author{
Koteswara R. Gurijala \\ Department of Botany \& Microbiology, University of \\ Oklahoma, Norman, Oklahoma, USA, and Department of \\ Mathematics \& Statistics, University of North Florida, \\ Jacksonville, FL, USA
}

\section{Ping Sa}

Department of Mathematics \& Statistics, University of North Florida, Jacksonville, FL, USA

\section{Melanie R. Mormile}

Department of Botany \& Microbiology, University of Oklahoma, Norman, OK, USA. Present address: Department of Biological Sciences, University of Missouri-Rolla, MO, USA

Keywords - Anaerobic biodegradation; hydrogen; landfill; methane; multiple regression analysis; municipal solid waste; refuse; statistical modeling

\author{
Corresponding author: Koteswara R. Gurijala, Alpha \\ Therapeutic Corporation, 2450 Lillyvale Avenue, Los \\ Angeles, CA 90032, USA \\ (E-mail: rao.gurijala@alphather.com)
}

Received 16 July 1999 , accepted in revised form 29 January 2000

\section{Introduction}

Landfilling of municipal solid waste (MSW) is a widely practiced means of its disposal. The United States Environmental Protection Agency (USEPA) estimated that about
$60 \%$ of the MSW produced in 1994 in the United States was disposed of in landfills (US EPA 1996). Approximately onehalf of MSW is typically composed of cellulose and hemicellulose (Fairweather \& Barlaz 1988; Barlaz et al. 1989), which are considered readily degradable in the 
environment. It is generally assumed that this organic fraction of the refuse is degraded by indigenous anaerobic microorganisms, because oxygen, if present, is restricted to the uppermost regions in landfills. However, it has been shown that refuse components, which are otherwise considered readily degradable, can sometimes persist for surprisingly long periods of time in landfills owing to several environmental factors that limit microbial activity (Suflita et al. 1992; Gurijala \& Suflita 1993). Landfills designed to overcome such limitations will certainly increase microbial metabolic activity and subsequently allow efficient refuse degradation. Hence, complete understanding of factors affecting microbial metabolism in landfills is of critical importance in designing new landfills.

Several metabolic groups of bacteria carry out a complex series of reactions during the anaerobic degradation of MSW, in which hydrogen and volatile fatty acids (VFA) are produced as transient intermediates (McInerney \& Bryant 1980; Harper \& Pohland 1986; Mormile et al. 1996). The smooth functioning of these ecosystems greatly relies upon the balance between the production and consumption of these intermediates (Kasper \& Wuhrmann 1978; Labib et al. 1992; Kramer \& Conrad 1993). Disturbances to such balance lead to hydrogen and VFA accumulation, which can negatively influence terminal electron accepting processes (TEAP). For instance, hydrogen partial pressures exceeding $10^{-4}$ atm $\left(80.7 \mathrm{nM}\right.$ of dissolved $\mathrm{H}_{2}$ ) cause VFA accumulation, while those below $10^{-4}$ atm favor TEAP (Kasper \& Wuhrmann 1978; McInerney \& Bryant 1980; Harper \& Pohland 1986; Zehnder \& Stumm 1988; Krylova $\&$ Conrad 1998). VFA accumulation under a high hydrogen atmosphere, in turn, results in a $\mathrm{pH}$ decrease that is inhibitory to methanogenic bacteria and methanogenesis (Mosey 1982; Switzenbaum et al. 1990; Mormile et al. 1996).

Apparent steady-state concentrations of hydrogen $\left(\mathrm{ASSCH}_{2}\right)$ were used to indicate imbalances of methanogenic fermentations (Strong \& Cord-Ruwisch 1995; Mormile et al. 1996; Cord-Ruwisch et al. 1997) and to determine dominant TEAP in a variety of environments (Lovley et al. 1994; Jakobsen et al. 1998) because of its key role in anaerobic catabolism (see Background section below). Despite its importance, environmental factors influencing $\mathrm{ASSCH}_{2}$, especially in landfill ecosystems, have been rather poorly understood. Available information, however, showed that organic overloading and presence of toxic material inhibit methanogenesis in landfills and digesters via hydrogen and VFA accumulation (Mclnerney \& Bryant 1980; Mosey 1982; Harper \& Pohland 1986; Switzenbaum et al. 1990; Strong \& Cord-Ruwisch 1995; Mormile et al. 1996; Cord-Ruwisch et al. 1997). Temperature was the only other environmental variable of which the effect on $\mathrm{ASSCH}_{2}$ was studied (Westermann 1994). In wetland sediment slurries, hydrogen production increased by a factor of 18 when the incubation temperature was raised from $2^{\circ} \mathrm{C}$ to $37^{\circ} \mathrm{C}$. However, the syntrophic degradation reactions of VFA remained exergonic, once the corresponding hydrogen concentration reached a steady state at the temperatures tested.

Information on the relative significance of multiple environmental factors simultaneously influencing hydrogen production during refuse degradation is not available, although such information is necessary in effectively controlling accelerated hydrogen production. By controlling accelerated hydrogen production, the probability of uncoupling the metabolic reactions necessary for refuse methanogenesis is reduced and methane production can be optimized. Therefore, identification and evaluation of the relative significance of environmental determinants governing $\mathrm{ASSCH}_{2}$ during refuse degradation, presented in this study, will be extremely useful in designing landfills for improved methane recoveries.

\section{Background}

The anaerobic biodegradation of MSW is carried out by several metabolic groups of bacteria (Zehnder et al. 1982; Barlaz 1997). The first group of bacteria hydrolyzes polymers such as cellulose and hemicellulose to their constituent monomers (Colberg 1988; McInerney 1988). These bacteria are the primary fermentative or hydrolytic bacteria (Schink 1997). The resulting monomers are further fermented to organic acids such as VFA and alcohols by the secondary fermentative bacteria or fatty acid oxidizing bacteria (FAOB). The FAOB convert these organic acids and alcohols to acetate, hydrogen and carbon dioxide (Dolfing 1988; Schink 1997).

The terminal group of bacteria complete the mineralization of refuse by converting the products of FAOB to methane and carbon dioxide. The terminal group of bacteria comprise methanogenic bacteria (Oremland 1988), sulfatereducing bacteria (Widdel 1988), iron/manganese-reducing bacteria (Ghiorse 1988), and nitrate-reducing (Tiedje 1988) bacteria. Methanogenic bacteria can produce methane either from acetate, or from hydrogen and carbon dioxide (Zehnder et al. 1982; Thauer 1998; Conrad 1999; Wolfe 1999). All other terminal group bacteria degrade acetate and 
other organic carbon at the expense of reducing appropriate electron acceptors. These electron-accepting processes carried out by the terminal group of bacteria are collectively known as TEAP.

Hydrogen is a critical though transient intermediate in refuse degradation. It is produced in the acetogenic dehydrogenation reactions and is consumed by terminal group of bacteria during TEAP. Acetogenic dehydrogenations of organic acids and alcohols in landfill environments are thermodynamically inhibited at hydrogen concentrations above $80.7 \mathrm{~nm}$, which occurs when these anaerobic systems become overloaded with organic carbon. This leads to the accumulation of organic acids, which in turn reduces the $\mathrm{pH}$ to a level inhibitory to methanogenic bacteria and the methanogenesis (Mormile et al. 1996). For refuse degradation to occur smoothly, the hydrogen concentration must be maintained below $80.7 \mathrm{nM}$. A higher accumulation of this gas is indicative of fermentation imbalances resulting in the inhibition of methanogenesis from refuse.

\section{Materials and methods}

The data analyzed in this study and the methods used to obtain the data were previously published (Suflita et al. 1992; Gurijala \& Suflita 1993; Mormile et al. 1996). Samples of MSW were collected from various sites and depths at the Fresh Kills Landfill, Staten Island, New York, USA, in October 1989. A bucket auger was used to drill down to the desired depth in order to obtain the samples. Fourteen boreholes were drilled in the landfill, and samples were collected at approximately $3-\mathrm{m}$ intervals. The refuse was passed through a coarse sieve $(5 \times 5 \mathrm{~cm})$ before being collected in plastic buckets containing an O-ring sealing lid. The headspace of the refuse-filled buckets was exchanged with oxygen-free nitrogen prior to their transport by overland courier to the laboratory, where they were stored at room temperature (Suflita et al. 1992; Gurijala \& Suflita 1993).

Anaerobic refuse incubation vessels were constructed by joining a standard plumbing end cap (PVC plastic, $7.6 \mathrm{~cm}$ ) to a reducing union $(7.6$ to $5 \mathrm{~cm}$ ). Refuse material (200 to $300 \mathrm{~g}$ ) was placed in the vessels while they were inside a portable anaerobic glovebag (AtmosBag, Aldrich Chemical Co., Milwaukee, Wisconsin, USA), which was constantly purged with nitrogen. The head space of each vessel was initially oxygen-free nitrogen. The vessels were incubated at room temperature and the headspace methane and hydrogen were monitored at regular intervals (Gurijala \& Suflita 1993; Mormile et al. 1996).

All statistical analyses were performed on the main frame computer at the University of North Florida using MS Windows Network version of the SAS program (SAS Institute 1990). A multiple regression model that explained the vast majority of variation in and predicted most of the observed $\mathrm{ASSCH}_{2}$ (dependent variable) was developed (Gurijala et al. 1997). The independent variables significantly correlated with $\mathrm{ASSCH}_{2}$ from the refuse samples were selected by the application of forward selection, backward elimination, stepwise procedure, coefficient of determination $\left(R^{2}\right)$ and conceptual predictive (Cp-statistic) criteria, with $\alpha$ values set at 0.1 to 0.5 (Mallows 1964; Neter et al. 1996). Examining $p$-values of the $t$-statistics refined the selection of variables.

Once the independent variables significantly associated with $\mathrm{ASSCH}_{2}$ were selected, a second-order model was developed on the basis of partial regression plots and the residual plots. SAS procedure 'PROC UNIVARIATE', with 'NORMAL' option, Box-Cox transformations (Box \& Cox 1964) and the residual plots revealed that the data did not need any transformation to satisfy the normality and equal variance assumptions. Each of the variables in the second-order model was then coded to reduce multicollinearity as explained by Neter et al. (1996).

All possible linear, square, and cross-product terms of the independent variables in the second-order model were analyzed again on the basis of forward selection, backward elimination, step-wise procedure, $R^{2}$ criterion, and $\mathrm{Cp}$ statistic and by the examination of partial regression leverage plots and the $p$-values of $t$-statistics. Then the variables in the model were tested for possible outliers and multicollinearity by variance inflation factors (Cook 1979) and all the standard outlier-detection procedures provided by the SAS procedure 'PROC REG' with 'INFLUENCE' option (SAS Institute 1990).

The assumptions of the second-order model, namely the random errors $\left(\varepsilon_{i}\right)$ are independently and normally distributed with mean zero $\left[E\left(\varepsilon_{i}\right)=0\right]$ and a constant variance $\left[V\left(\varepsilon_{i}\right)=\sigma^{2}\right]$, were tested by using univariate procedure, residual plots, normal probability plots and Box-Cox transformations.

The model parameter estimates were computed by using the least-squares method (Masili-Libelli 1992; Saez \& Rittmann 1992). Then the coded variables were transformed to their original scale to derive the final fitted model.

Comparing the coefficients of pattial determinations 
(R-values), $t$-statistics and $p$-values of the model parameter estimates (Neter et al. 1996; Gurijala et al. 1997) determined the relative contribution of each model variable towards $\mathrm{ASSCH}_{2}$. The R-value for each independent variable $X$ was computed as follows (Neter et al. 1996):

$R=\left[\operatorname{SSR}_{(X \mid \text { all }}\right.$ the other variables $\left.)\right] /$

[SSE (all the other variables)]

where:

$\left[\operatorname{SSR}_{(X \mid \text { all the other variables })}\right]=$ the extra sum of squares of adding $X$ to the model when all the other variables are already included and is given by $\left[S S E_{\text {(all the other variables) }}\right]-$ [SSE (all the variables)

$\left[S S E_{\text {(all the other variables) }}\right]=$ error sum of squares for the model with all the other independent variables except $X$

$\left[S S E_{\text {(all the variables) }}\right]=$ error sum of squares for the model with all the independent variables including $X$.

\section{Results}

The descriptive statistics and the definition of the variables were given in Table 1 . The $\mathrm{ASSCH}_{2}$ in refuse incubations varied greatly with a mean of $6.4 \mu \mathrm{M}$ and a standard deviation of $14.0 \mu \mathrm{M}$. Pearson correlations indicated that $\mathrm{pH}$ and $\mathrm{NMO}$ are significantly, albeit negatively, associated with the $\mathrm{ASSCH}_{2}$. None of the other variables considered showed any significant relationship with the $\mathrm{ASSCH}_{2}$ (Table 1). Because Pearson correlations are insufficient to determine simultaneous effects of multiple variables, landfill data was analyzed by multiple regression techniques.
In order to develop a multiple regression model from the landfill data, it was necessary to first identify significant variables simultaneously influencing $\mathrm{ASSCH}_{2}$. The significant variables out of 11 landfill characteristics (Table 1) were selected by using five different statistical methods. The forward selection procedure identified CLR, NMO, AMY, NIT and EST to be significantly associated with $\mathrm{ASSCH}_{2}$ (Table 2). The backward elimination procedure selected NMO and CLR, whereas the step-wise procedure showed CLR, NMO and AMY to be significant factors associated with $\mathrm{ASSCH}_{2}$.

The $R^{2}$-values and $\mathrm{Cp}$ statistics of models containing all possible combinations of independent variables further refined the variable selection (Table 3 ). Thus, models $C$, $\mathrm{D}$ and $\mathrm{E}$ showed the highest $R^{2}$ and lowest Cp. Further increase in the number of variables neither increased $R^{2}$ nor decreased $\mathrm{Cp}$ values substantially. Therefore, models $\mathrm{C}, \mathrm{D}$ and $E$ were selected to be adequate starting points in the development of the final model.

The Pearson correlation matrix revealed a strong linear relationship between CLR and VS $\left(r^{2}=0.9388\right)$. In addition, the variance inflation factors (VIF) for VS (35.516) and CLR (39.146) far exceeded their tolerance levels $(0.028$ for VS and 0.026 for CLR) indicating multicollinearity between these two factors. As deletion of one of the two variables effectively eliminates multicollinearity, the models 1 and 2 (see below) containing CLR or VS were individually evaluated to determine which of the two variables should be deleted.

Partial regression plots and $t$-tests suggested that the effects of AMY and EST on $\mathrm{ASSCH}_{2}$ in the presence of the

Table 1. Descriptive statistics and definition of the variables*

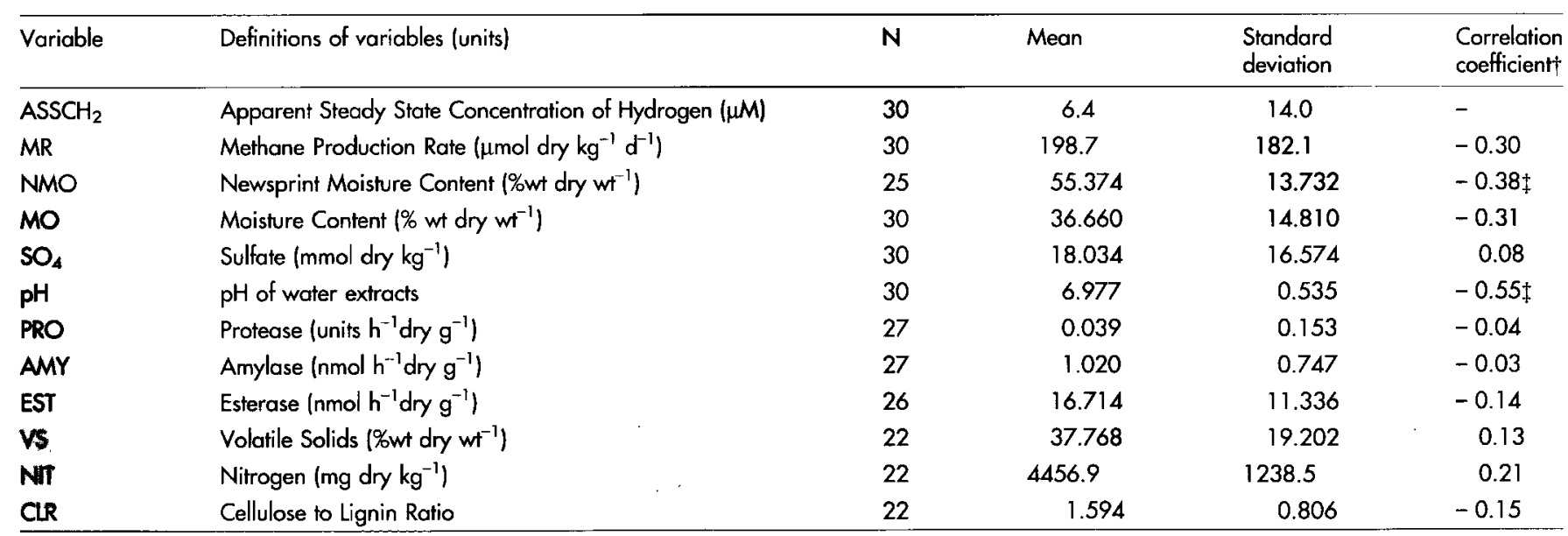

"Data from Gurijala et al. (1997), Mormile et al. (1996), and Suflita et al. (1992).

tPearson correlation coefficient between $\mathrm{ASSCH}_{2}$ and the variable considered.

$\$$ Significant at $\alpha=0.05$. 
Table 2. Selection of variables" associating with $\mathrm{ASSCH}_{2}$ by forward selection, backward elimination, and stepwise procedures

\begin{tabular}{lll}
\hline Selection method & Variable & $p$-value of $f$ statistic \\
\hline & CLR & 0.0053 \\
& NMO & 0.0025 \\
& AMY & 0.1437 \\
Forward Selection $(\alpha=0.5)$ & NIT & 0.2615 \\
& EST & 0.3917 \\
Backward elimination $(\alpha=0.1)$ & NMO & 0.0025 \\
& CIR & 0.0014 \\
Stepwise procedure $(\alpha=0.15)$ & CLR & 0.0053 \\
& NMO & 0.0025 \\
& AMY & 0.1437
\end{tabular}

*See Table 1 for the definition of variables.

other variables were insignificant. Thus, model $\mathrm{C}$ was selected and model $\mathrm{D}$ was reduced to model $\mathrm{B}$ in the further development of the final fitted model (Table 3 ).

The residual plots and the partial regression plots suggested the addition of higher-order (square, crossproduct, or both) terms of the significant independent variables to the model to better account for the variation observed in $\mathrm{ASSCH}_{2}$. Therefore, the higher-order terms of the significant independent variables were tested for inclusion in the model and were confirmed by the examination of residual and partial regression plots. The variables thus selected were included in the models 1 and 2 after being coded by subtracting the mean and dividing by the standard deviation. The coding effectively eliminated multicollinearity among the higher power terms as indicated by the Pearson correlation matrix and VIF.

$\mathrm{ASSCH}_{2}=\beta_{0}+\beta_{1} \mathrm{TNMO}+\beta_{2} \mathrm{TNMO}^{2}+\beta_{3} \mathrm{TVS}^{2}+\beta_{4}$ $\mathrm{TNIT}^{2}+\varepsilon$

$$
\begin{aligned}
& \mathrm{ASSCH}_{2}=\beta_{0}+\beta_{1} \mathrm{TNMO}+\beta_{2} \mathrm{TNMO}^{2}+\beta_{3} \mathrm{TCLR}+\beta_{4} \\
& \mathrm{TCLR}^{2}+\varepsilon
\end{aligned}
$$

where:

$\mathrm{TVS}^{2}, \mathrm{TNMO}^{2}$ and $\mathrm{TNIT}^{2}$ are coded square terms of VS, NMO, and NIT, respectively

TNMO is coded NMO

$\beta_{0}$ to $\beta_{4}$ are the parameters

$\varepsilon$ is the random error of the model.

The assumptions involved in model 1, which contained VS, were reasonable. The assumption that the observations are independent is true because the plots of observed $\mathrm{ASSCH}_{2}$ production vs. the residuals did not show significant patterns (Fig. 1). Analysis using SAS UNIVARIATE procedure with the NORMAL option revealed that the assumption of observations being normally distributed was also reasonable. The assumption that the mean of the random error is zero $\left[E_{(\varepsilon i)}=0\right]$ cannot be tested, because the sum of residuals always equals zero. However, this assumption was considered reasonable because all the other assumptions were true (Neter et al. 1996). The equal variance assumption was tested by separating the observations into two groups by level of independent variables, and by comparing the sample variances of each half by an $F$-test. The F-test showed that there is no significant difference between the variances of the two halves of the data set indicating that the equal variance assumption is valid.

Partial regression plots of model 1 showed significant association between the independent variables and $\mathrm{ASSCH}_{2}$ (Fig. 2). This model also explained $95 \%$ of the variation in observed $\mathrm{ASSCH}_{2}$ as indicated by its $R^{2}$ value (0.9549). In addition, a scatter plot of observed vs. predicted values of

\begin{tabular}{|c|c|c|c|c|}
\hline Model & Variable(s) & $(\mathrm{P}) \dagger$ & $R^{2}$ & $C_{p}$ \\
\hline A & CLR & 2 & 35.796 & 4.82 \\
\hline B & NMO, CLR & 3 & 63.097 & -2.03 \\
\hline D & NMO, AMY, CLR & 4 & 67.847 & -1.57 \\
\hline E & NMO, AMY, VS, NIT & 5 & 71.643 & -0.802 \\
\hline $\mathbf{F}$ & NMO, pH, VS, NIT & 5 & 71.247 & -0.674 \\
\hline H & NMO, pH, AMY, EST, VS, NIT & 7 & 73.252 & 2.675 \\
\hline I & $\mathrm{MR}, \mathrm{NMO}, \mathrm{MO}, \mathrm{SO}_{4}, \mathrm{pH}, \mathrm{VS}, \mathrm{NIT}$ & 8 & 74.315 & 4.331 \\
\hline$J$ & $\mathrm{MR}, \mathrm{NMO}, \mathrm{MO}, \mathrm{SO}_{4}, \mathrm{pH}, \mathrm{AMY}, \mathrm{NIT}, \mathrm{CLR}$ & 9 & 75.098 & 6.077 \\
\hline $\mathrm{K}$ & $\mathrm{MR}, \mathrm{NMO}, \mathrm{MO}, \mathrm{SO}_{4}, \mathrm{pH}, \mathrm{AMY}, \mathrm{VS}, \mathrm{NIT}, \mathrm{CLR}$ & 10 & 75.330 & 8.002 \\
\hline $\mathbf{L}$ & $\mathrm{MR}, \mathrm{NMO}, \mathrm{MO}, \mathrm{SO}_{4}, \mathrm{pH}, \mathrm{PRO}, \mathrm{AMY}, \mathrm{VS}, \mathrm{NIT}, \mathrm{CLR}$ & 11 & 75.334 & 10.000 \\
\hline M & All 11 variables & 12 & 75.336 & 12.000 \\
\hline
\end{tabular}

Table 3. Selection by $R^{2}$ criterion and Cp statistic of variables ${ }^{*}$ associated with $\mathrm{ASSCH}_{2}$

*See Table 1 for the definition of variables.

tNumber of parameters include the intercept 


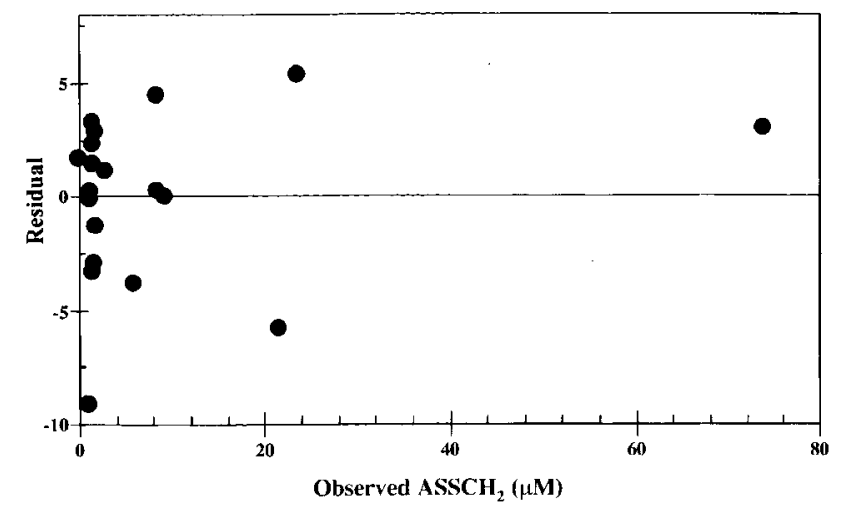

Fig. 1. Plot of residuals vs. observed apparent steady-state concentrations of hydrogen $\left(\mathrm{ASSCH}_{2}\right)$ showing the variance is independent and constant.

$\mathrm{ASSCH}_{2}$ showed that model 1 predicted $98 \%\left(r^{2}=0.9795\right)$ of the observed $\mathrm{ASSCH}_{2}$ (Fig. 3).

On the other hand, the inherent assumptions for model 2, which included CLR, were found to be invalid. In addition, model 2 was less efficient than model 1 in explaining total variation in and predicting observed $\mathrm{ASSCH}_{2}$. Hence, model 1 with VS was used in the evaluation of relative significance of significant variables associated with $\mathrm{ASSCH}_{2}$.

The relative importance of the significant factors affecting $\mathrm{ASSCH}_{2}$ during refuse degradation was evaluated from model 1 . The coded variables were decoded to their original scale before calculating least-square estimates of the parameters. The $t$-statistics and $p$-values of the parameter estimates, and the $R$-values, indicated the relative contribu-

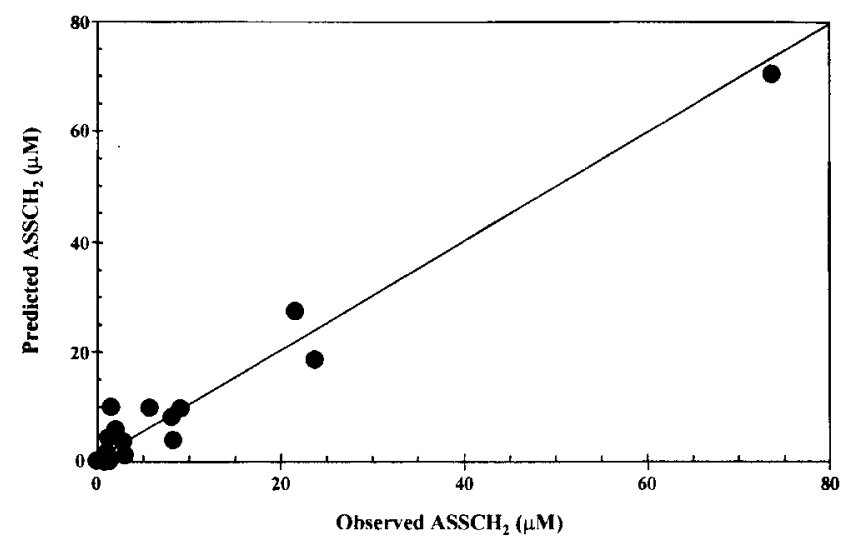

Fig. 3. The relationship between predicted and observed apparent steady stale concentrations of hydrogen $\left(\mathrm{ASSCH}_{2}\right)$. Line of equality shown.

tion of the independent variables present in model 1 (Table 4). The higher the $|t|$ value, the higher the $R$-value, and the lower the $p$-value the more the contribution of that independent variable. Thus, NMO contributed the most, followed by $\mathrm{NMO}^{2}$ and $\mathrm{VS}^{2}$ and the least by $\mathrm{NIT}^{2}$ towards $\mathrm{ASSCH}_{2}$. The parameter estimates indicated that the influence of $\mathrm{VS}^{2}$ and $\mathrm{NMO}^{2}$ was positive, while that of $\mathrm{NMO}$ and $\mathrm{NIT}^{2}$ was negative on $\mathrm{ASSCH}_{2}$ (Table 4).

\section{Discussion}

Environmental factors contributing towards the accumulation of hydrogen during anaerobic refuse degradation will

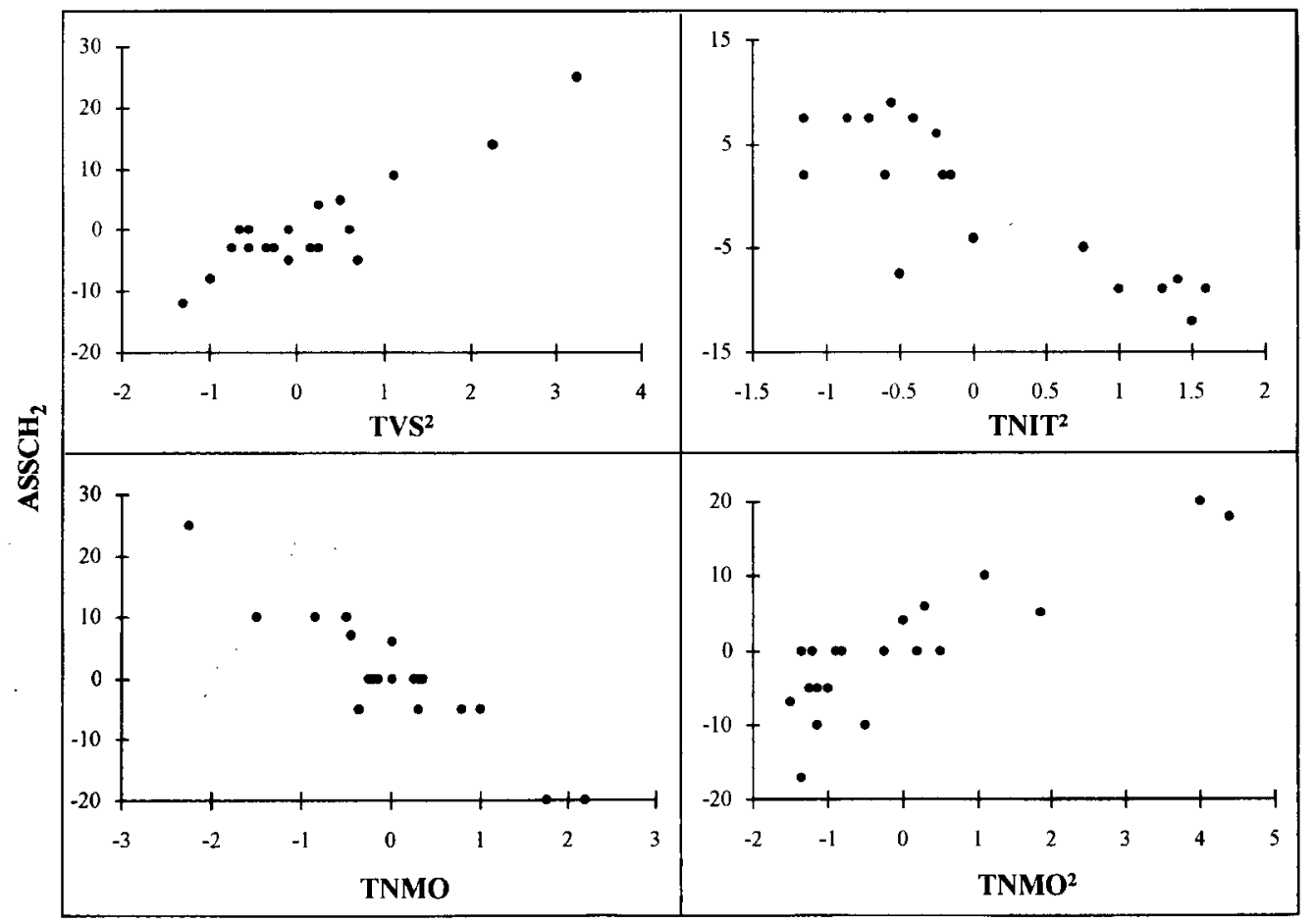

Fig. 2. Partial regression plots showing the relationship between apparent steady-state concentrations of hydrogen $\left(\mathrm{ASSCH}_{2}\right)$ and independent variables in the final fitted model. See Table 1 for the description and units of $x$-axis labels. 
Table 4. Parameter estimates and coefficients of partial determination of independent variables in the final model

\begin{tabular}{|c|c|c|c|c|c|}
\hline Variable & Parameter & $\begin{array}{l}\text { Parameter } \\
\text { estimate }\end{array}$ & $\dagger$ & $p \ddagger$ & R-Value§ \\
\hline Intercept & $\beta_{0}$ & 4.394 & 2.584 & 0.0207 & - \\
\hline NMO & $\beta_{1}$ & -8.906 & -9.748 & 0.0001 & 0.7832 \\
\hline $\mathrm{NMO}^{2}$ & $\beta_{2}$ & 4.207 & 7.758 & 0.0001 & 0.7396 \\
\hline$v s^{2}$ & $\beta_{3}$ & 5.835 & 6.359 & 0.0001 & 0.6158 \\
\hline $\mathrm{NIT}^{2}$ & $\beta_{4}$ & -6.483 & -6.392 & 0.0001 & 0.5093 \\
\hline
\end{tabular}

"Parameters were calculated by using least-squares method.

†The $t$-statistic.

\$The $p$-value arising from a $t$-test of the null hypothesis that $\beta=0$.

$\S$ The coefficient of partial determination.

also inhibit methanogenesis, as the accumulation of the former clearly indicates fermentation imbalances leading to the inhibition of the latter in a variety of ecosystems (Strong \& Cord-Ruwisch 1995; Mormile et al. 1996; Cord-Ruwisch et al. 1997). Pearson correlation analysis was performed on landfill data to identify significant environmental factors affecting $\mathrm{ASSCH}_{2}$. This analysis revealed that $\mathrm{pH}$ had significant negative influence on $\mathrm{ASSCH}_{2}$ indicating that the samples producing hydrogen at high concentrations are often acidic. Mormile et al. (1996) have shown that acidic refuse samples accumulated more hydrogen than those with neutral or alkaline $\mathrm{pH}$ and that this acidity is due to the accumulation of VFA. The negative relationship between $\mathrm{ASSCH}_{2}$ and $\mathrm{pH}$ is due to VFA accumulation, which is caused by a hydrogen accumulation in excess of $10^{-4} \mathrm{~atm}$ (Thauer et al. 1977; McInerney \& Bryant 1980; Zehnder \& Stumm 1988; Krylova \& Conrad 1998).

However, Pearson correlations are insufficient to assess the relative significance of multiple factors simultaneously affecting $\mathrm{ASSCH}_{2}$. Therefore, multiple regression analysis, which essentially involved development of a second-order regression model, was used to evaluate the relative significance of 11 landfill variables. The regression model incorporated significant linear, square, and/or cross-product terms of NMO, NIT, and VS, and successfully captured the trends of the data set as shown by its ability to account for $95 \%$ of the total variation in and predicted $98 \%$ of the observed $\mathrm{ASSCH}_{2}$. Mathematical and kinetic models have been developed from data obtained in experiments, which involved artificially manipulated variables, mainly for the purpose of understanding the physiological basis of organic carbon degradation (Belevi \& Baccini 1989; El-Fadel et al. 1989; Young 1989). Statistical models constructed from the field data, such as the one developed in this study, overcome limitations inherent to mathematical and kinetic models in the evaluation of relative importance of environmental factors. In fact, multiple regression models developed from landfill data have been successfully used to determine the relative importance of environmental factors in refuse methanogenesis (Gurijala et al. 1997) and to evaluate simultaneous effects of $\mathrm{pH}$ and temperature to predict acetate and butyrate production from cheese-processing wastewater (Hwang \& Hansen 1997).

The evaluation of relative contributions of significant variables in the regression model revealed that $\mathrm{ASSCH}_{2}$ was greatly influenced by $\mathrm{NMO}$ followed by $\mathrm{NMO}^{2}, \mathrm{VS}^{2}$, and the least by $\mathrm{NIT}^{2}$. The influence exerted by NMO, and $\mathrm{NIT}^{2}$ was negative, while that of $\mathrm{NMO}^{2}$ and $\mathrm{VS}^{2}$ was positive on $\mathrm{ASSCH}_{2}$. The factors negatively influencing $\mathrm{ASSCH}_{2}$ should also enhance refuse methanogenesis and vice versa, because non-methanogenic samples accumulated high amounts of hydrogen (Mormile et al. 1996). Thus, NMO and $\mathrm{NIT}^{2}$ should favor, while $\mathrm{NMO}^{2}$ and $\mathrm{VS}^{2}$ should inhibit refuse methanogenesis. However, moisture content of the total refuse sample, rather than that associated with only newsprint (the NMO) affects refuse methanogenesis more significantly than any other variable tested (Gurijala et al. 1997). This suggested that while total moisture content of the sample enhanced the activity of the methanogens, the NMO enabled methanogens as well as those involved in other TEAP to remain active hydrogen scavengers. In either case it is not surprising that moisture positively affected hydrogen scavenging as well as methanogenic activities, inasmuch as moisture is an essential requirement for landfilled refuse fermentations (Barlaz et al. 1990; Senior et al. 1990; Gurijala \& Suflita 1993; Gurijala et al. 1997). The negative contribution of $\mathrm{NIT}^{2}$ towards $\mathrm{ASSCH}_{2}$ indicated that anaerobic decomposition of nitrogen-rich refuse samples maintains low $\mathrm{ASSCH}_{2}$ and high methane production. Again, this is not unexpected as nitrogen is an essential nutrient for efficient biodegradation and bioassimilation of organic carbon (Stevenson 1986; Burton \& Watson-Craik 1996).

The positive influence of $\mathrm{VS}^{2}$ and $\mathrm{NMO}^{2}$ showed that 
high concentration of VS and NMO enhanced hydrogen accumulation and so inhibited methanogenesis. This inhibitory effect of high VS content on refuse methanogenesis was also observed previously (Gurijala et al. 1997). Moreover, the inhibition of methanogenesis in anaerobic environments overloaded with organic carbon as evidenced by hydrogen accumulation is widely known (Mosey 1982; Harper \& Pohland 1986; Senior et al. 1990; Switzenbaum et al. 1990; Mormile et al. 1996; Gurijala et al. 1997). In fact, hydrogen partial pressures exceeding $10^{-4}$ atm thermodynamically inhibit VFA oxidation (Thauer et al. 1977; Zehnder \& Stumm 1988; Krylova \& Conrad 1998), which in turn inhibit methanogenesis by decreasing $\mathrm{pH}$ below the tolerance levels of methanogenic bacteria (Senior et al. 1990; Mormile et al. 1996). The high NMO content may also have contributed towards organic overloading by exposing cellulose and starch contained in the newsprint to landfill bacteria (Smook 1989). The results presented here provide statistical evidence for the hydrogen and VFA involvement in the inhibition of refuse methanogenesis in landfills.

\section{References}

Barlaz, M. A. (1997) Microbial studies of landfills and anaerobic refuse decomposition. In: Hurst, C. J. Knudsen, G. R. McInerney, M. J. Stetzenbach, L. D. \& Walter, M. V. (eds) Manual of Enwironmental Microbiology. Washington, DC, USA: American Society for Microbiology, pp. 541-557.

Barlaz, M. A., Ham, R. K. \& Schaefer, D. M. (1989) Mass balance analysis of decomposed refuse in laboratory scale lysimeters. Joumal of Environmental Engineering ASCE 115, 1088-1102.

Barlaz, M. A., Ham, R. K. \& Schaefer, D. M. (1990) Methane production from refuse: a review of enhancement techniques and microbial dynamics. Critical Reviews in Environmental Control 19, 557-584.

Belevi, H. \& Baccini, P. (1989) Long-term behavior of municipal solid waste landfills. Waste Management $\mathcal{E}$ Research 7, 43-56.

Box, G. E. P. \& Cox, D. R. (1964) An analysis of transformations. Journal of the Royal Statistical Society B26, 211-243.

Burton, S. A. Q. \& Watson-Craik, I. A. (1996) Nitrogen balances in landfill refuse. In: Fowler, G. D. (eds) Proceedings of the 1995 Society for Chemical Industry Conference, Current Trends in Contaminated Land. London, UK: Sociery for Chemical Industry, pp. 33-38.

Colberg, P. J. (1988) Anaerobic microbial degradation of cellulose, lignin, oligolignols, and monoaromatic lignin derivatives. In: Zehnder, A. J. B. (ed. ) Biology of Anaerobic Microorganisms. New York, USA: John Wiley \& Sons, pp. 333-372.

Conrad, R. (1999) Contribution of hydrogen to methane production and control of hydrogen concentrations in methanogenic soils and sediments. FEMS Microbiology Ecology 28, 193-202.

Cook, R. D. (1979) Influential observations in linear regression. Journal of the American Statistical Association 74, 169-174.

Cord-Ruwisch, R., Mercz, T. I., Hoh, C.-Y. \& Strong, G. E. (1997) Dissolved hydrogen concentration as an on-line control parameter for the automated operation and optimization of anaerobic digesters. Biotechnology and Bioengineering 56, 626-634.

Dolfing, J. (1988) Acetogenesis. In: Zehnder, A. J. B. (ed. ) Biology of
As with any statistical model, the regression model presented here is specific for Fresh Kills landfill. However, the model clearly identifies moisture levels as measured by newsprint moisture content, volatile solids, and nitrogen content as significant impactors of landfill $\mathrm{ASSCH}_{2}$. The statistical model developed here shows that the combination of optimum moisture levels, avoidance of organic overloading, and sufficient nitrogen content are required to control the overproduction of hydrogen, and ultimately increase methane yields from refuse degradation in landfills.

\section{Acknowledgments}

We thank J. M. Suflita, F. Concannon, R. K. Ham, M. R. Norman, P. R. Fritsche, A. C. Palmisano, B. S. Schwab, D. A. Maruscik, W. L. Rathje and W. W. Hughes for their contributions to the original landfill data. We also thank $M$. A. Barlaz, M. A. Hamilton and H. A. Cash for reviewing the manuscript.

Anaerobic Microorganisms. New York, USA: John Wiley \& Sons, pp. 417-468.

El-Fadel, M., Findikakis, A. N. \& Lackie, J. O. (1989) A numerical model for methane production in managed sanitary landfills. Waste Management $\mathcal{E}$ Research 7, 31-42.

Fairweather, R. J. \& Barlaz, M. A. (1988) Hydrogen sulfide production during decomposition of landfill inputs. Joumal of Environmental Engineering ASCE 124, 353-361.

Ghiorse, W. C. (1988) Microbial reduction of manganese and iron. In: Zehnder, A. J. B. (ed. ) Biology of Anaerobic Microorganisms. New York, USA: John Wiley \& Sons, pp. 305-331.

Gurijala, K. R., Sa, P. \& Robinson, J. A. (1997) Statistical modeling of methane production from landfill samples. Applied and Environmental Microbiology 63, 3797-3803.

Gurijala, K. R. \& Sullita, J. M. (1993) Environmental factors influencing methanogenesis from refuse in landfill samples. Environmental Science and Technology 27, 1176-1181.

Harper, S. R. \& Pohland, F. G. (1986) Recent developments in hydrogen management during anaerobic biological wastewater treatment. Biotechnology and Bioengineering 28, 585-602.

Hwang, S. \& Hansen, C. L. (1997) Modeling and optimization in anaerobic bioconversion of complex substrates to acetic acid and butyric acids. Biotechnology and Bioengineering 54, 451-460.

Jakobsen, R., Albrechtsen, H.-J., Rasmussen, M., Bay, H., Bjerg, P. L. \& Christensen, T. H. (1998) $\mathrm{H}_{2}$ concentrations in a landfill leachate plume (Grinsted, Denmark): in situ energetics of terminal electron acceptor processes. Environmental Science and Technology 32, 21422148.

Kasper, H. F. \& Wuhrmann, K. (1978) Product inhibition in sludge digestion. Microbial Ecology 4, 241-248.

Kramer, H. \& Conrad, R. (1993) Measurement of dissolved $\mathrm{H}_{2}$ concentrations in methanogenic environments with a gas diffusion probe. FEMS Microbiology Ecology 12, 149-158. 
Krylova, N. I. \& Conrad, R. (1998) Thermodynamics of propionate degradation in methanogenic environments with a gas diffusion probe. FEMS Microbiology Ecology 26, 281-288.

Labib, F., Ferguson, J. F., Benjamin, M. M., Merigh, M. \& Ricker, N. L. (1992) Anaerobic butyrate degradation in a fluidized-bed reactor: effects of increased concentrations of $\mathrm{H}_{2}$ and acetate. Environmental Science and Technology 26, 369-376.

Lovley, D. R., Chapelle, F. H. \& Woodward, J. C. (1994) Use of dissolved $\mathrm{H}_{2}$ concentrations to determine distribution of microbially catalyzed redox reactions in anoxic groundwater. Environmental Science and Technology 28, 1205-1210.

Mallows, C. L. (1964) Some comments on C(p). Technometrics 15, 661-675.

Masili-Libelli, S. (1992) Parameter estimation of ecological models. Ecological Modeling 62, 233-258.

McInerney, M. J. (1988) Anaerobic hydrolysis and fermentation of fats and proteins. In: Zehnder, A. J. B. (ed. ) Biology of Anaerobic Microorganisms. New York, USA: John Wiley \& Sons, pp. 373-415.

McInerney, M. J. \& Bryant, M. P. (1980) Review of methane fermentation fundamentals. In: Wise, D. L. (ed. ) Fuel Gas Production from Biomass. Boca Raton, Florida, USA: CRC Press, pp. 20-46.

Mormile, M. R., Gurijala, K. R., Robinson, J. A., McInerney, M. J. \& Suflita, J. M. (1996) The importance of hydrogen in landfill fermentations. Applied and Environmental Microbiology 62, 1583-1588.

Mosey, F. E. (1982) New developments in the anaerobic treatment of industrial wastes. Joumal of Water Pollution Control Federation 81, 540550.

Neter, J., Kutner, M. H., Nachtsheim, C. J. \& Wassermann, W. (1996). Applied Linear Statistical Models (fourth edition). Boston, USA: Irwin Publishers.

Oremland, R. S. (1988) Biogeochemistry of methanogenic bacteria. In: Zehnder, A. J. B. (ed. ) Biology of Anaerobic Microorganisms. New York, USA: John Wiley \& Sons, pp. 641-705.

Saez, P. B. \& Rittmann, B. E. (1992) Model-parameter estimation using least squares. Water Research 26, 789-796.

SAS Institute (1990) SAS User's Guide: Statistics. Cary, North Carolina, USA: SAS Institute.

Schink, B. (1997) Energetics of syntrophic cooperation in methanogenic degradation. Microbiology and Molecular Biology Reviews 61, 262-280.

Senior, E., Watson-Craik, I. A. \& Kasali, G. B. (1990) Control/promotion of the refuse methanogenic fermentation. Critical Reviews in Biotechnology 10, 93-118.

Smook, G. A. (1989). Handbook for Pulp and Paper Technologists. Atlanta,
Georgia, USA: TAPPI and Montreal, Canada: Canadian Pulp and Paper Association.

Stevenson, F. J. (1986). Cycles of Soil: Carbon, Nitrogen, Phosphorus, Sulfur, Micronutrients. New York, USA. John Wiley \& Sons.

Strong, G. E. \& Cord-Ruwisch, R. (1995) An in-situ dissolved-hydrogen probe for monitoring anaerobic digesters under overload conditions. Biotechnology and Bioengineering 45, 63-68.

Suflita, J. M., Gerba, C. P., Ham, R. K., Palmisano, A. C., Rathje, W. L. \& Robinson, J. A. (1992) The world's largest landfill: multidisciplinary investigation. Environmental Science Technology 26, 1486-1494.

Switzenbaum, M. S., Giraldo-Gomez, E. \& Hickey, R. F. (1990) Monitoring of the anaerobic methane fermentation process. Enzyme and Microbial Technology 12, 722-730.

Thauer, R. K. (1998) Biochemistry of methanogenesis: a tribute to Marjory Stephenson. Microbiology (UK) 144, 2377-2406.

Thauer, R. K., Jungermann, K. \& Dekker, K. (1977) Energy conversion in chemotrophic anaerobic bacteria. Bacteriological Reviews 41, 100-180.

Tiedje, J. M. (1988) Ecology of denitrification and dissimilatory nitrate reduction. In: Zehnder, A. J. B. (ed. ) Biology of Anaerobic Microorganisms. New York, USA: John Wiley \& Sons, pp. 179-244.

US Environmental Protection Agency (1996) Characterization of municipal solid waste in the United States: 1995 Update. Report no. EPA/530-R96-001. Washington, DC, USA: US Environmental Protection Agency.

Westermann, P. (1994) The effect of incubation temperature on steady-state concentrations of hydrogen and volatile fatty acids during anaerobic degradation in slurries from wetland sediments. FEMS Microbiology Ecology 13, 295-302.

Widdel, F. (1988) Microbiology and ecology of sulfate- and sulfur-reducing bacteria. In: Zehnder, A. J. B. (ed. ) Biology of Anaerobic Microorganisms. New York, USA: John Wiley \& Sons, pp. 469-585.

Wolfe, R. S. (1999) Anaerobic life: a centennial view. Joumal of Bacteriology $181,3317-3320$.

Young, A. (1989) Mathematical modeling of landfill degradation. Joumal of Chemical Technology and Biotechnology 46, 189-208.

Zehnder, A. J. B., Ingvorsen, K. \& Marti, T. (1982) Microbiology of methane bacteria. In: Hughes, D. E. \& Stafford, D. A. (eds) Anaerobic Digestion. Amsterdam, The Netherlands: Elsevier Biomedical Press BV, pp. 45-68.

Zehnder, A. J. B. \& Stumm, W. (1988) Geochemistry and biogeochemistry of anaerobic habits. In: Zehnder, A. J. B. (ed. ) Biology of Anaerobic Microorganisms. New York, USA: John Wiley \& Sons, pp. 1-38. 